\title{
Image Segmentation of Mammographic Images Using Kekre'S Proportionate Error Technique on Probability Images
}

\author{
Dr.H.B.Kekre ${ }^{1}$, Saylee M. Gharge ${ }^{2}$ and Tanuja K. Sarode ${ }^{3}$
}

\begin{abstract}
Mammography is well known method for detection of breast tumors. Early detection and removal of the primary tumor is an essential and effective method to enhance survival rate and reduce mortality. In this paper, proposed algorithm uses probability of mammographic image as input for vector quantization .For region forming Kekre's Proportionate Error (KPE) algorithm is used and codebook of size 128 is formed .Further this 128 clusters were used for region merging using KPE algorithm for reclustering .To separate tumor ,post processing is done by morphological operations. For this tumor sectional area is calculated and center point is compared with LBG algorithm for segmentation of mammographic images.
\end{abstract}

Index Terms - Mammographic images, segmentation, vector quantization

\section{INTRODUCTION}

Of all diagnostic methods currently available, mammography is the most reliable method for early detection [1], [2]. Of the breast cancers that are visible in retrospective studies, however, $10 \%$ to $30 \%$ are missed during mammographic interpretation [3]-[5], and 40\% of the missed cancers appear as masses on the mammograms. In an attempt to lower the cost and increase effectiveness, investigators are developing alternative techniques to improve mammographic imaging [6]. Computer-aided diagnostic (CAD) methods have been proposed as one low cost tool to aid radiologists in film interpretation [7], [8]. CAD can be used to alert radiologists to locations of suspicious lesions and provides a second reading which has been found to reduce misdiagnosis. However, a well-trained computer program (which can screen a large volume of mammograms accurately and reproducibly) is needed in order for CAD to become practical in clinical settings. Such a program has yet to be developed.

The fundamental step in many CAD methods is the segmentation of possible target signals in the input image. Detection of a subtle mass on a mammogram is a difficult task because mammograms contain edges of low

Manuscript received April 1, 2010.

Dr.H.B.Kekre ${ }^{1}$ Senior Professor, MPSTME, NMIMS University, Vile-Parle (w), Mumbai- 400056, India; (e-mail: hbkekre@yahoo.com).

Saylee M. Gharge ${ }^{2}$, ${ }^{2} \mathrm{Ph} . \mathrm{D}$. Scholar, MPSTME, NMIMS University, Lecturer, V.E.S.I.T, Mumbai-400071, India (e-mail: sayleegharge73@yahoo.co.in).

Tanuja K. Sarode ${ }^{3}$ is ${ }^{3} \mathrm{Ph}$.D. Scholar, MPSTME, NMIMS University, Assistant Professor, TSEC, Mumbai-400050, India (e-mail: tanuja_0123@yahoo.com). signal-to-noise ratio and complicated structured background. A number of image processing methods have been proposed to perform this task. S. M. Lai et al [9] and W. Qian et al [10] have proposed using modified and weighted median filtering, respectively, to enhance the digitized image prior to object identification. D. Brzakovic et al [11] used thresholding and fuzzy pyramid linking for mass localization and classification. Other investigators have proposed using the asymmetry between the right and left breast images to determine possible mass locations. Yin et al. uses both linear and nonlinear bilateral subtraction [12] while the method by Lau et al. [13] relies on "structural asymmetry" between the two breast images. Recently Kegelmeyer [14] has reported promising results for detecting speculated lesions based on local edge characteristics and Laws texture features $[15,16]$. The above methods produced a true positive detection rate of approximately $90 \%$. The work we have done till now is to propose a segmentation process which identifies on a mammogram the opaque areas, suspect or not, present in the image using vector quantization[17-26].

Vector Quantization (VQ) [27-35] is an efficient technique for data compression and has been successfully used in various applications such as index compression [36, 37]. VQ has been very popular in a variety of research fields such as speech recognition and face detection [38, 39]. VQ is also used in real time applications such as real time video-based event detection [40] and anomaly intrusion detection systems [41], image segmentation [42-45], speech data compression [46], content based image retrieval CBIR [47] and face recognition [48].Hence in propose method vector quantization is used for region forming and region merging.

The rest of the paper is organized as follows. Section II describes proposed algorithm used for image segmentation of mammographic images. Followed by the experimental results for mammographic images are in section III and section IV concludes the work.

\section{Proposed AlgorithM}

In this proposed algorithm probability of original image is used for grouping pixels into regions and then the image of probability is formed. For image segmentation Equalized probability image is used as an input image for further segmentation.

The proposed technique has three steps to follow:

1. Region forming using vector quantization

technique

2. Region merging using reclustering. 
3. Post Processing.

A. Probability

For complete image probability of particular $i^{\text {th }}$ gray level which is given by:

$$
\text { Probability } \mathrm{P}(\mathrm{i})=\frac{X_{i}}{M X N}
$$

Where $X \mathrm{i}$ is number of pixels for $\mathrm{i}^{\text {th }}$ gray levels, $\mathrm{M}$ and $\mathrm{N}$ are no. of rows and columns of the image.

After calculating this the image is formed which contains probability values for that particular gray level instead of gray level in the image and it is displayed as probability image as shown in Figure 2(b) for original image in Figure 2(a) and Figure 2(c) is histogram equalized probability image.

\section{B. Vector Quantization}

Vector Quantization (VQ) techniques employ the process of clustering. VQ is a technique in which a codebook is generated for each image. A codebook is a representation of the entire image containing a definite pixel pattern which is computed according to a specific VQ algorithm. The image is divided into fixed sized blocks that form the training vector. The generation of the training vector is the first step to cluster formation on these training vectors clustering methods is applied and codebook is generated.

\section{B.1.Linde-Buzo-Gray (LBG) Algorithm}

The method most commonly used to generate codebook is the Linde-Buzo-Gray (LBG) algorithm which is also called as Generalized Lloyd Algorithm (GLA). For the purpose of explaining this algorithm, we are considering two dimensional vector space as shown in Figure 1. In this algorithm centroid is computed as the first codevector $\mathrm{C}_{1}$ for the training set. In Figure 1 two vectors $\mathrm{v}_{1} \& \mathrm{v}_{2}$ are generated by adding constant error to the codevector $\mathrm{C}_{1}$. Euclidean distances of all the training vectors are computed with vectors $v_{1} \& v_{2}$ and two clusters are formed based on nearest of $v_{1}$ or $v_{2}$. Procedure is repeated for these two cluster to generate four new clusters. This procedure is repeated for every new cluster until the required size of codebook is reached or specified MSE is reached.

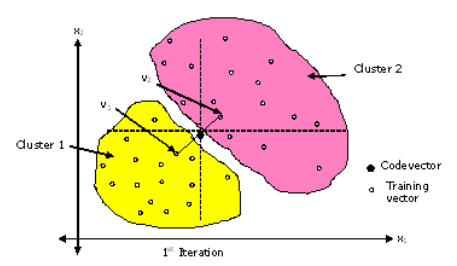

Figure 1. LBG for 2 dimensional case

The drawback of this algorithm is that the cluster elongation is $+135^{\circ}$ to horizontal axis in two dimensional cases. This results in inefficient clustering.

\section{B.2. Kekre's Proportionate Error (KPE) algorithm}

In this codebook generation algorithm, proportionate error is added to the centroid to generate two vectors v1 \& v2. Magnitude of members of the centroid decides the error ratio. Hereafter the procedure is same as that of LBG. While adding proportionate error a safe guard is also introduced so that neither v1 nor v2 go beyond the training vector space. This removes the disadvantage of the LBG.

The size of codebook is set to 128. Training vectors are reassigned to encoding regions in every iteration. Once the code book size reaches 128 the process is stopped. In the original image pixel value is replaced by the encoding region number to which the pixel is assigned.

\section{Region merging:}

For region merging codebook of size 128 is used as an input to KPE algorithm where we are merging these clusters to form new codebook of size 8.Further image for each codevector is formed by considering minimum value of each codevector as a reference and by adding two more levels on the top of the first codevectors which is greatest gray level value i.e. 255 and at the bottom of the last codevectors which is lowest gray level i.e. 0. Total nine images were generated for one equalized probability image.

\section{Post Processing:}

If some unwanted regions are present in the segmented image then post processing is required to achieve only tumor in the final image. For that morphological operations are used .For proper boundary detection, canny edge detector is used .Then by using actual physical size of mammograms area of the tumor is calculated.

\section{RESULTS}

Mammography images from mini-mias database were used in this paper for implementation of LBG algorithm and proposed algorithm using equalized probability image for tumor demarcation. Fig.2(a) shows original image with tumor. It has fatty tissues as background. Class of abnormality present is CIRC which means well-defined/ circumscribed mass. This image has malignant abnormality. Location of the center of abnormality is $(338,314)$ for $x, y$ image co-ordinates. Approximate radius is 56(in pixels) of a circle enclosing the tumor. Proposed algorithm is tasted on thirty mammographic images which consist of micro calcification with specific tumors.

First probability of image is achieved as shown in Figure 2(b ) for original image. Since the values are very low further processed with histogram equalization for probability, where it is possible to differentiate between normal and abnormal masses displayed in Figure 2(c). In third step vector quantization is used for region forming. For vector quantization KPE is used instead of LBG. The segmentation thus obtained is comparatively better than LBG as shown in Figure 3(a)-(e).The validation of the work has been done by visual inspection of the segmented image by an expert radiologist.

For extraction of only tumor, morphological operations were performed on Figure 3(a). Figure 4 (a) indicates binary gradient image by using Sobel operator where as Figure 4(b) shows dilated gradient image for Figure 4(a)processing it further finally segmented image is obtained in Figure 4(e).

Figure 5 (b) indicates superimposed segmented image on original image .To differentiate tumor it is indicated in green 
color.

\section{Results for sectional area calculation for Proposed}

Algorithm [For Figure 4(e)]

Total no. of pixel in the image $=4802409$

No. of pixels with gray level $0=473322$
No. of pixels with gray level $255=6918$

Enter Length of actual image/object in $\mathrm{cm}=18$

Enter Breadth of actual image/object in $\mathrm{cm}=24$

Total image $/$ object area $=432$ sq. $\mathrm{cm}$

Area of image with gray level $0=425.7769$ sq. $\mathrm{cm}$

Area of image with gray level $255=6.2231 \mathrm{sq} . \mathrm{cm}$

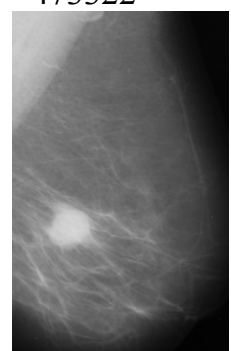

(a)

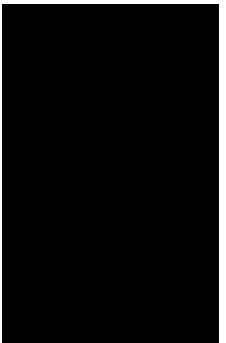

(b)

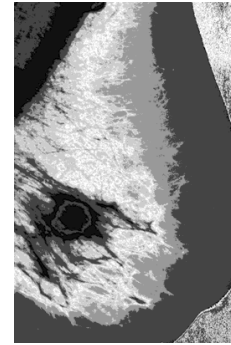

(c)

Figure 2 : (a)Original Image,(b) Probability Image,(c)Equalized probability image

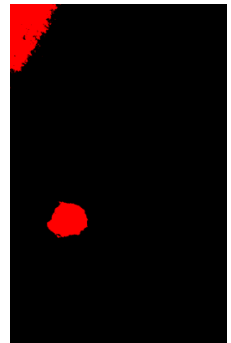

(a)

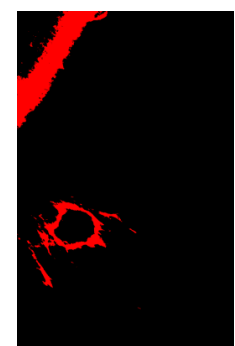

(b)

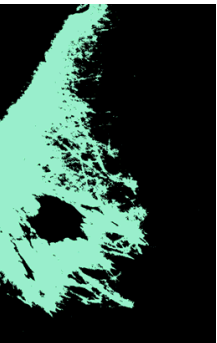

(c)

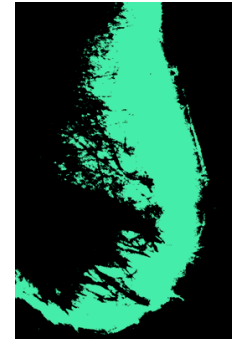

(d)

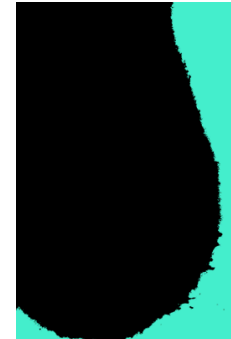

(e)

Figure 3 : (a) Image for $2^{\text {nd }}$ codevector, (b)Image for $3^{\text {rd }}$ codevector, (c)Image for $4^{\text {th }}$ codevector,

(d) Image for $5^{\text {th }}$ codevector, (e)Image for $6^{\text {th }}$ codevector

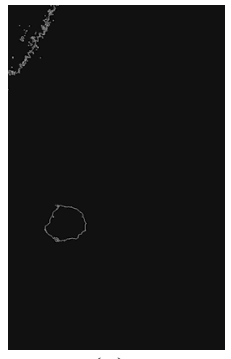

(a)

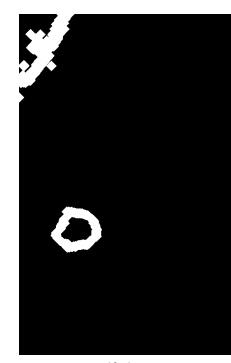

(b)

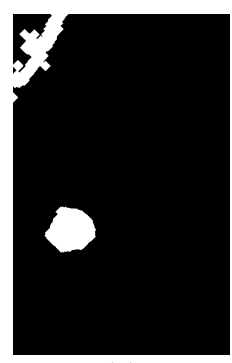

(c)

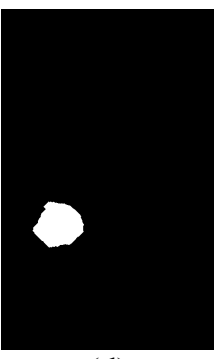

(d)

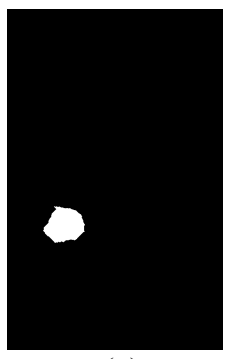

(e)

Figure 4: (a) Binary gradient image for Figure 3(a), (b) Dilated gradient mask,(c)Binary image with filled , (d)Cleared border image, (e) Final segmented image

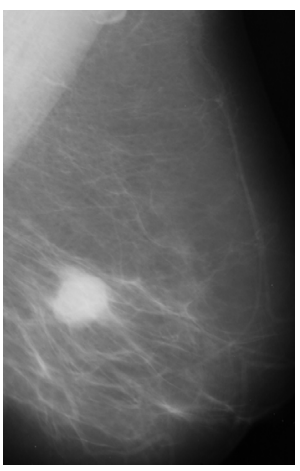

(a)

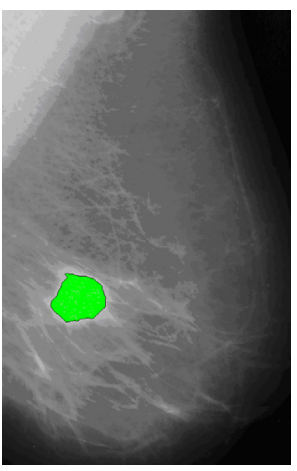

(b)

Figure 5 : (a)Original Image , (b)Superimposed image

\begin{tabular}{|c|c|c|}
\hline $\begin{array}{c}\text { Co-ordinate } \\
\text { s }\end{array}$ & \multicolumn{2}{|c|}{ Name of the algorithm } \\
\cline { 2 - 3 } & LBG & $\begin{array}{c}\text { Proposed Algorithm using } \\
\text { KPE }\end{array}$ \\
\hline Xmax & 361 & 386 \\
\hline Xmin & 322 & 281 \\
\hline Ymax & 348 & 366 \\
\hline Ymin & 293 & 273 \\
\hline$X c$ & 341 & 334 \\
\hline
\end{tabular}




\begin{tabular}{|l|l|l|}
\hline Yc & 320 & 319 \\
\hline
\end{tabular}

\section{TABLE 1: CO-ORDINATES OF BOUNDARY AND CENTER POINT}

for calculation of sectional area, final image consists of only tumor thus it becomes very easy to find out it.Required input from user is physical length and breadth of the mammogram. Even center point for Tumor using $\mathrm{x}, \mathrm{y}$ co-ordinates system can be compared with LBG segmentation for proposed algorithm as shown in Table 1.

\section{CONCLUSION}

From results specifically by observing Figure 5(b) which clearly indicates the segmented tumor. Table 1 gives comparison of co-ordinates of boundary and center point for LBG and proposed algorithm using KPE. This shows that center point by proposed algorithm is closer to the center point $(338,314)$ which is mentioned in the mini-mias database for the specific image .For this tumor sectional area is $6.22 \mathrm{sq} . \mathrm{cm}$ by considering length $\mathrm{x}$ breadth is $18 \mathrm{~cm} \mathrm{x} 24 \mathrm{~cm}$. This proposed algorithm does not lead to over segmentation or under segmentation.

\section{ACKNOWLEDGEMENT}

The authors would like to record their appreciation to Dr. Manisha Munde for her help in validating the results.

\section{REFERENCES}

[1] L. Tab\& and P. B. Dean, "The control of breast cancer through mammography screening: What is the evidence," Radiloogy Clin. N. Amer.,vol. 25, no. 5, pp. 993-1005, Sept. 1987.

[2] J. Caseldine, R. Blamey, E. Roebuck, and C. Elston, Breast Diseasefor Radiographers. Toronto, Canada: Wright, 1988.

[3] J. E. Martin, M. Moskowitz, and J. R. Milbrath, "Breast cancer missed by mammography," Am. J. Roentgeno., vol. 132, pp. 737-739, May 1979.

[4] R. E. Bird, T. W. Wallace, and B. C. Yankaskas, "Analysis of cancers missed at screening mammography," Radiol., vol. 184, pp. 613-617,Sept. 1992.

[5] M. G. Wallis, M. T. Walsh, and J. R. Lee, "A review of false negative mammography in a symptomatic population," Clin. Radiol., vol. 44, pp. $13-15,1991$.

[6] F. Shtem, C. Stelling, B. Goldberg, and R. Hawkins, "Novel technologies in breast imaging: National Cancer Institute perspective," in Second Post-Graduate Course Syllabus, Soc. of Breast Imaging, Orlando, FL, New York Grune and Stratton, 1987.May 1995, pp. 153-156.

[7] H. P. Chan, K. Doi, C. J. Vvbornv, R. A. Schmidt, C. E. Metz. K. L. Lam, T. Ogura, Y. Wu, and H. MacMahon, "Improvement in radiologists' detection of clustered micro-calcifications on mammograms," Investigative Radiol., vol. 25, no. 10, pp. 1102-1110, Oct. 1990.

[8] W. P. Kegelmeyer Jr., "Computer detection of stellate lesions in mammograms," in Proc. SPIE Biomed. Image Processing, 1992, vol 1660, pp. 446454.

[9] S. M. Lai, X. Li, and W. F. Bischof, "On techniques for detecting circumscribed masses in mammograms," ZEEE Trans. Med. Zmag., vol 8 , no. 4, pp. 377-386, Dec. 1989

[10] W. Qian, L. P. Clarke, M. Kallergi, and R. A. Clark, “ Tree-structured nonlinear filters in digital mammography, IEEE Trans. Med. Zmag., vol.13, no. 1, pp. 25-36, Mar. 1994

[11] D. Brzakovic, X. M. Luo, and P. BBzrakovic, "An approach to automated detection of tumors in mammography," IEEE Trans. Med. Imag., vol. 9, no. 3, pp. 233-241, Sept. 1990.

[12] F. F. Yin, M. L. Giger, K. Dol, C. E. Metz, R. A. Vyborny, and C. J. Schmidt, "Computerized detection of masses in digital mammograms: Analysis of bilateral subtraction images," Med. Phys., vol. 18, no. 5, pp. 955-963, Sept. 1991.
[13] T. K. Lau and W. F. Bischof, "Automated detection of breast tumors using the asymmetry approach,' Comput. Biomed. Res., vol. 24, pp.273-295, 1991.

[14] W. P. Kegelmeyer Jr., J. M. Pruneda, P. D. Bourland, A. Hillis, M. W. Riggs, and M. L. Nipper, "Computer-aided mammographic screening for spiculated lesions," Radiol., vol. 191, no. 2, pp. 331-337, May 1994.

[15] D. Marr and E. Hildreth, "Theory of edge detection," in Proceeding Royal Society, London., vol. 207, pp. 187-217, 1980.

[16] J. Lunscher and M. P. Beddoes, "Optimal edge detector design: Parameter selection and noise effects," IEEE Trans. Pattem Anal. Machine Intell., vol. 8, no. 2, pp. 154-176, Mar. 1986.

[17] H. B. Kekre , Saylee Gharge, "Segmentation of MRI Images using Probability and Entropy as Statistical parameters for Texture analysis," Advances in Computational sciences and Technology(ACST),Volume 2,No.2,pp:219-230,2009, http://www.ripublication.com/acst.htm

[18] H. B. Kekre, Saylee Gharge, "Selection of Window Size for Image Segmentation using Texture Features," International Conference on Advanced Computing \&Communication Technologies(ICACCT-2008) Asia Pacific Institute of Information Technology SD India, Panipat ,08-09 November,2008.

[19] H. B. Kekre, Saylee Gharge, "Image Segmentation of MRI using Texture Features," International Conference on Managing Next Generation Software Applications, School of Science and Humanities, Karunya University, Coimbatore, Tamilnadu ,05-06 December,2008.

[20] H. B. Kekre, Saylee Gharge , "Statistical Parameters like Probability and Entropy applied to SAR image segmentation," International Journal of Engineering Research \& Industry Applications (IJERIA), Vol.2,No.IV, pp.341-353.

[21] H. B. Kekre, Saylee Gharge , "SAR Image Segmentation using co-occurrence matrix and slope magnitude," ACM International Conference on Advances in Computing, Communication \& Control (ICAC3-2009), pp.: 357-362, 23-24 Jan 2009, Fr. Conceicao Rodrigous College of Engg. Available on ACM portal.

[22] H. B. Kekre, Tanuja K. Sarode ,Saylee Gharge, "Detection and Demarcation of Tumor using Vector Quantization in MRI Images" ,International Journal of Engineering Science and Technology(IJEST),Volume 2,No.2,pp:59-66,2009.

[23] H. B. Kekre, Saylee Gharge, "Tumor Demarcation of Mammography Images Using Entropy with Different Window Sizes", Second International Conference on Emerging Trends in Engineering and Technology, ICETET-2009, held at Raisoni College of Engineering, Nagpur, India, pp.: 889-894, 16-18 December 2009. Avaliable at IEEE Xplore.

[24] H. B. Kekre, Tanuja K. Sarode, Saylee Gharge, "Kekre's Fast Codebook Generation Algorithm for Tumor Detection in Mammography Images", International Conference and Workshop on Emerging Trends in Technology (ICWET 2010), at Thakur College of Engineering and Technology (TCET), $26 \& 27$ th February 2010, the paper will be uploaded on ACM portal .

[25] H. B. Kekre, Tanuja K. Sarode, Saylee Gharge, "Image Segmentation of MRI Images using Vector Quantization Techniques" International Conference on Contours of Computing Technology, 13th-14th March 2010, at Babasaheb Gawade Institute of Technology. Paper will be available on Springer Link Digital Library.

[26] H. B. Kekre, Tanuja K. Sarode, Saylee Gharge, "Tumor Demarcation in Mammographic Images using Vector Quantization Technique on Entropy Images" International Conference on Contours of Computing Technology, 13th-14th March 2010, at Babasaheb Gawade Institute of Technology. Paper will be available on Springer Link Digital Library.

[27] R. M. Gray, "Vector quantization", IEEE ASSP Mag., pp.: 4-29, Apr. 1984

[28] Y. Linde, A. Buzo, and R. M. Gray, "An algorithm for vector quantizer design,” IEEE Trans.Commun., vol. COM-28, no. 1, pp.: 84-95, 1980

[29] H.B.Kekre, Tanuja K. Sarode, "New Fast Improved Clustering Algorithm for Codebook Generation for Vector Quantization", International Conference on Engineering Technologies and Applications in Engineering, Technology and Sciences, Computer Science Department, Saurashtra University, Rajkot, Gujarat. (India), Amoghsiddhi Education Society, Sangli, Maharashtra (India), 13th 14th January 2008.

[30] H. B. Kekre, Tanuja K. Sarode, "New Fast Improved Codebook Generation Algorithm for Color Images using Vector Quantization," 
International Journal of Engineering and Technology, vol.1, No.1, pp.: 67-77, September 2008.

[31] H. B. Kekre, Tanuja K. Sarode, "Fast Codebook Generation Algorithm for Color Images using Vector Quantization," International Journal of Computer Science and Information Technology, Vol. 1, No. 1, pp.: 7-12, Jan 2009 .

[32] H. B. Kekre, Tanuja K. Sarode, "An Efficient Fast Algorithm to Generate Codebook for Vector Quantization," First International Conference on Emerging Trends in Engineering and Technology, ICETET-2008, held at Raisoni College of Engineering, Nagpur, India, pp.: 62- 67, 16-18 July 2008. Avaliable at IEEE Xplore.

[33] H. B. Kekre, Tanuja K. Sarode, "Fast Codebook Generation Algorithm for Color Images using Vector Quantization," International Journal of Computer Science and Information Technology, Vol. 1, No. 1, pp.: 7-12, Jan 2009

[34] H. B. Kekre, Tanuja K. Sarode, "Fast Codevector Search Algorithm for 3-D Vector Quantized Codebook", WASET International Journal of cal Computer Information Science and Engineering (IJCISE), Volume 2, No. 4, pp.: 235-239, Fall 2008. Available: http://www.waset.org/ijcise.

[35] H. B. Kekre, Tanuja K. Sarode, "Fast Codebook Search Algorithm for Vector Quantization using Sorting Technique", ACM International Conference on Advances in Computing, Communication and Control (ICAC3-2009), pp: 317-325, 23-24 Jan 2009, Fr. Conceicao Rodrigous College of Engg., Mumbai. Available on ACM portal

[36] Jim Z.C. Lai, Yi-Ching Liaw, and Julie Liu, "A fast VQ codebook generation algorithm using codeword displacement", Pattern Recogn. vol. 41, no. 1, pp.: 315-319, 2008.

[37] C.H. Hsieh, J.C. Tsai, Lossless compression of VQ index with search order coding, IEEE Trans. Image Process. vol. 5, No. 11, pp.: $1579-1582,1996$.

[38] Chin-Chen Chang, Wen-Chuan Wu, "Fast Planar-Oriented Ripple Search Algorithm for Hyperspace VQ Codebook", IEEE Transaction on image processing, vol 16, no. 6, pp.: 1538-1547, June 2007.

[39] C. Garcia and G. Tziritas, "Face detection using quantized skin color regions merging and wavelet packet analysis," IEEE Trans. Multimedia, vol. 1, no. 3, pp.: 264-277, Sep. 1999.

[40] H. Y. M. Liao, D. Y. Chen, C. W. Su, and H. R. Tyan, "Real-time event detection and its applications to surveillance systems," in Proc. IEEE Int. Symp. Circuits and Systems, Kos, Greece, pp.: 509-512, May 2006.

[41] J. Zheng and M. Hu, "An anomaly intrusion detection system based on vector quantization," IEICE Trans. Inf. Syst., vol. E89-D, no. 1, pp.: 201-210, Jan. 2006.

[42] [42]H. B. Kekre, Tanuja K. Sarode, Bhakti Raul, "Color Image Segmentation using Kekre's Fast Codebook Generation Algorithm Based on Energy Ordering Concept", ACM International Conference on Advances in Computing, Communication and Control (ICAC3-2009), pp.: 357-362, 23-24 Jan 2009, Fr. Conceicao Rodrigous College of Engg., Mumbai. Available on ACM portal.

[43] H. B. Kekre, Tanuja K. Sarode, Bhakti Raul, "Color Image Segmentation using Kekre's Algorithm for Vector Quantization", International Journal of Computer Science (IJCS), Vol. 3, No. 4, pp. 287-292, Fall 2008. Available: http://www.waset.org/ijcs.

[44] H. B. Kekre, Tanuja K. Sarode, Bhakti Raul, "Color Image Segmentation using Vector Quantization Techniques Based on Energy Ordering Concept" International Journal of Computing Science and Communication Technologies (IJCSCT) Volume 1, Issue 2, pp: 164-171, January 2009.

[45] H. B. Kekre, Tanuja K. Sarode, Bhakti Raul, "Color Image Segmentation Using Vector Quantization Techniques", Advances in Engineering Science Sect. C (3), pp.: 35-42, July-September 2008.

[46] H. B. Kekre, Tanuja K. Sarode, "Speech Data Compression using Vector Quantization", WASET International Journal of Computer and Information Science and Engineering (IJCISE), vol. 2, No. 4, pp.: 251-254, Fall 2008. available: http://www.waset.org/ijcise.

[47] H. B. Kekre, Ms. Tanuja K. Sarode, Sudeep D. Thepade, "Image Retrieval using Color-Texture Features from DCT on VQ Codevectors obtained by Kekre's Fast Codebook Generation", ICGST-International Journal on Graphics, Vision and Image Processing (GVIP), Volume 9, Issue 5, pp.: 1-8, September 2009. Available online at http://www.icgst.com/gvip/Volume9/Issue5/P1150921752.

[48] H. B. Kekre, Kamal Shah, Tanuja K. Sarode, Sudeep D. Thepade, "Performance Comparison of Vector Quantization Technique - KFCG with LBG, Existing Transforms and PCA for Face Recognition", International Journal of Information Retrieval (IJIR), Vol. 02, Issue 1, pp.: 64-71, 2009.

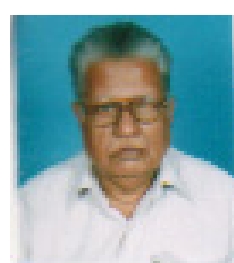

ADr. H. B. Kekre has received B.E. (Hons.) in Telecomm. Engg. from Jabalpur University in 1958, M.Tech (Industrial Electronics) from IIT Bombay in 1960, M.S.Engg. (Electrical Engg.) from University of Ottawa in 1965 and Ph.D. (System Identification) from IIT Bombay in 1970. He has worked Over 35 years as Faculty of Electrical Engineering and then HOD Computer Science and Engg. at IIT Bombay. For last 13 years worked as a Professor in Department of Computer Engg. at Thadomal Shahani Engineering College, Mumbai. He is currently Senior Professor working with Mukesh Patel School of Technology Management and Engineering, SVKM's NMIMS University, Vile Parle(w), Mumbai, INDIA. His areas of interest are Digital Signal processing and Image Processing. He has more than 250 papers in National International Conferences / Journals to his credit. Recently six students working under his guidance have received best paper awards. Currently he is guiding ten Ph.D. students.

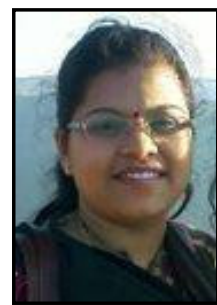

Ms. Saylee M. Gharge has received M.E. (Electronics and telecomm.) degree from Mumbai University in 2007, currently Pursuing Ph.D. from Mukesh Patel School of Technology, Management and Engineering, SVKM's NMIMS University, Vile-Parle (W), Mumbai She has more than 10 years of experience in teaching. Currently working as a Assistant Professor in department of electronics and telecommunication in Vivekanand Institute of Technology, Mumbai. Her areas of interest are Image Processing, Signal Processing. She has 30 papers in National/International Conferences/journal to her credit.

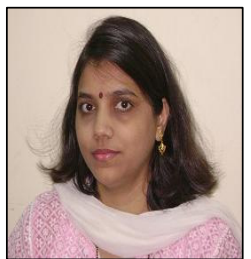

Tanuja K. Sarode has Received Bsc.(Mathematics) from Mumbai University in 1996, Bsc.Tech.(Computer Technology) from Mumbai University in 1999, M.E. (Computer Engineering) degree from Mumbai University in 2004, currently Pursuing Ph.D. from Mukesh Patel School of Technology, Management and Engineering, SVKM's NMIMS University, Vile-Parle (W), Mumbai, INDIA. She has more than 10 years of experience in teaching. Currently working as Associate Professor in Dept. of Computer Engineering at Thadomal Shahani Engineering College, Mumbai. She is life member of IETE, member of International Association of Engineers (IAENG) and International Association of Computer Science and Information Technology (IACSIT), Singapore. Her areas of interest are Image Processing, Signal Processing and Computer Graphics. She has 55 papers in National /International Conferences/journal to her credit. 